\title{
BMJ Open Collaboration and knowledge generation in an 18-year quality improvement research programme in Australian Indigenous primary healthcare: a coauthorship network analysis
}

\author{
Jodie Bailie (D) , ${ }^{1,2}$ Boyd Alexander Potts, ${ }^{1}$ Alison Frances Laycock (D) , \\ Seye Abimbola (1) , ${ }^{2,3}$ Ross Stewart Bailie (D) ," Frances Clare Cunningham (1) , \\ Veronica Matthews (D) , Roxanne Gwendalyn Bainbridge (D) , \\ Kathleen Parker Conte (D) , ${ }^{1,6}$ Megan Elizabeth Passey (D) , ${ }^{1}$ David Peiris (D) ${ }^{2,3}$
}

To cite: Bailie J, Potts BA, Laycock AF, et al. Collaboration and knowledge generation in an 18-year quality improvement research programme in Australian Indigenous primary healthcare: a coauthorship network analysis. BMJ Open 2021;11:e045101. doi:10.1136/ bmjopen-2020-045101

- Prepublication history and additional online supplemental material for this paper are available online. To view these files, please visit the journal online (http://dx.doi.org/10. 1136/bmjopen-2020-045101)

Received 24 September 2020 Revised 17 April 2021 Accepted 20 April 2021

A) Check for updates

(C) Author(s) (or their employer(s)) 2021. Re-use permitted under CC BY-NC. No commercial re-use. See rights and permissions. Published by BMJ.

For numbered affiliations see end of article.

Correspondence to

Ms Jodie Bailie;

jodie.bailie@sydney.edu.au

\section{ABSTRACT}

Objectives Though multidisciplinary research

networks support the practice and effectiveness of continuous quality improvement (CQI) programmes, their characteristics and development are poorly understood. In this study, we examine publication outputs from a research network in Australian Indigenous primary healthcare (PHC) to assess to what extent the research network changed over time.

Setting Australian CQI research network in Indigenous PHC from 2002 to 2019.

Participants Authors from peer-reviewed journal articles and books published by the network.

Design Coauthor networks across four phases of the network (2002-2004; 2005-2009; 2010-2014; 2015-2019) were constructed based on author affiliations and examined using social network analysis methods. Descriptive characteristics included organisation types, Indigenous representation, gender, student authorship and thematic research trends.

Results We identified 128 publications written by 308 individual authors from 79 different organisations. Publications increased in number and diversity over each funding phase. During the final phase, publication outputs accelerated for organisations, students, project officers, Indigenous and female authors. Over time there was also a shift in research themes to encompass new clinical areas and social, environmental or behavioural determinants of health. Average degree (8.1), clustering (0.81) and diameter (3) indicated a well-connected network, with a core-periphery structure in each phase $(p \leq 0.03)$ rather than a single central organisation (degree centralisation $=0.55-0.65$ ). Academic organisations dominated the core structure in all funding phases. Conclusion Collaboration in publications increased with network consolidation and expansion. Increased productivity was associated with increased authorship diversity and a decentralised network, suggesting these may be important factors in enhancing research impact

\section{Strengths and limitations of this study}

A study strength was the long time frame of 18 years of publications from an Australian quality improvement research network.

- To the best of our knowledge, this study is the first to describe a continuous quality improvement research network using coauthorship network analysis.

- Our analysis does not include the multiple affiliations of many of the authors and so may under-report the level of collaboration.

- Coauthorship is only one indicator of collaboration, though it has several advantages to relying on it as a proxy for assessing research collaboration including its verifiability, stability over time and availability in the public domain.

- Many other collaborative efforts are not reflected in coauthorship metrics, such as collaborations that continue to occur through coauthorship, grant submissions and conference presentations.

and advancing the knowledge and practice of CQI in PHC. Publication diversity and growth occurred mainly in the fourth phase, suggesting long-term relationship building among diverse partners is required to facilitate participatory research in CQI. Despite improvements, further work is needed to address inequities in female authorship and Indigenous authorship.

\section{INTRODUCTION}

Over the past two decades, continuous quality improvement (CQI) programmes have been widely taken up by primary healthcare (PHC) services caring for Aboriginal and Torres Strait Islander people (hereafter respectfully referred to as Indigenous people, 
acknowledging their cultural and historical diversity) across Australia. ${ }^{12}$ CQI-a set of methods for improving the quality of care, through continuous measurement and problem-solving techniques ${ }^{3}{ }^{4}$-has been found to improve the quality of care delivered in Indigenous PHC. ${ }^{15}$

While evidence indicates no single model of CQI outperforms others, the most successful applications of CQI are multisite and multifaceted approaches that aim to achieve change at various levels of the health system. ${ }^{6}$ We and others have argued the need for multidisciplinary research networks to support the practice and effectiveness of $\mathrm{CQI}^{67}$ and to foster coproduction and sharing of knowledge. However, despite research networks often being touted as a solution for enhancing knowledge translation into policy and practice, their characteristics and emergence over time are poorly understood. ${ }^{8-10}$ Furthermore, evaluation challenges can be considerable because research networks are often loosely defined and manifest in different forms with formal and informal organisational structures. ${ }^{11} 12$

We sought to better understand the development and growth of a multidisciplinary research network in Indigenous PHC quality improvement, and how these aspects reflected the vision of the network with respect to capacity strengthening, equity and membership diversity. Coauthorship network analysis offers one feasible strategy for evaluating the growth and emergence of research networks, because publications are well documented and reflect collaboration. ${ }^{13-15}$ The study uses coauthorship network analysis to examine the growth and change in an 18-year CQI research network in Australian Indigenous PHC. We address the question: How did the research network expand and change over time? Specifically we will investigate the extent to which the research network brought together people from a variety of organisations; the structural characteristics of the network; the level of equity in authorship relative to Indigenous status and gender; capacity strengthening efforts through examining student authorship; and changes in research themes over time.

\section{The setting}

Although Australia has a high-performing health system, underpinned by a universal health insurance scheme, it ranks low on measures of equity when compared with other Organisation for Economic Co-operation and Development nations. ${ }^{16}$ This ranking is reflected in consistent underperformance in addressing inequities in healthcare access, quality of care and outcomes for Indigenous people. ${ }^{17-19}$ These inequities are underpinned by a legacy of colonisation, land dispossession, displacement, disempowerment, social and economic exclusion and ongoing racial discrimination. ${ }^{19} 20$

To help address these inequities, the Audit and Best Practice in Chronic Disease (ABCD) participatory action research programme was initiated in 2002. Drawing on international evidence about the effectiveness of system-wide CQI approaches to improve the quality of PHC service delivery, ${ }^{21}$ the ABCD programme employed a systems approach to support the CQI efforts of PHC services established to provide care for Indigenous Australians. ${ }^{1622}$ Connected to this research programme, in 2010 a national, not-for-profit, CQI support entityOne21seventy-was established to support Indigenous PHC services in implementing CQI cycles using standardised, evidence-based, best practice clinical audit and systems assessment tools. Notably, 175 of the over 275 PHC centres involved provided the research network with deidentified data derived from their use of the CQI tools and processes. The studies published by network members reporting analyses of these data form a comprehensive picture of the quality of PHC received by Indigenous people around Australia. ${ }^{1}$ Between 2010 and 2016, $\mathrm{ABCD}$ research accounted for 42 of the $60(70 \%)$ peerreviewed publications identified in a systematic review on CQI in Indigenous PHC in Australia, ${ }^{2}$ and also made a significant contribution to international CQI research. ${ }^{23}$ Importantly, although there were demonstrated improvements in quality of care in some areas of clinical care, there was continuing wide variation between PHC centres and jurisdictions. ${ }^{15}$

Table 1 sets out the four distinct phases of the ABCD programme's evolution from 2002 to December 2019, its research aims, systems-strengthening dimensions and main findings. The intention of the resulting network was an 'open collaboration' that actively encourages cooperation with other organisations and individuals to help achieve the programme's aims. The current phase of research (2020-2024) is included in table 1 but was not part of this study.

\section{METHODS}

We used social network analysis, as described by Fonseca et $a l^{13}$ in their health sector coauthorship network analysis, to retrieve scientific publications, standardise entries for authors and organisations, visualise the network and calculate metrics.

\section{Data retrieval}

Details of peer-reviewed journal articles and books (the 'publications') were retrieved from administrative records held by the Centre for Research Excellence in Integrated Quality Improvement (CRE-IQI) coordinating centre, and included all publications published from 2002 to 2019.

\section{Data categorisation, standardisation and cleaning}

Publications were sorted into categories and research themes that were iteratively developed and defined by JB and RSB. We describe the process for categorisation of included publications below.

\section{Organisations}

The affiliations of the authors (as per their citation on publications) were coded into universities and research 


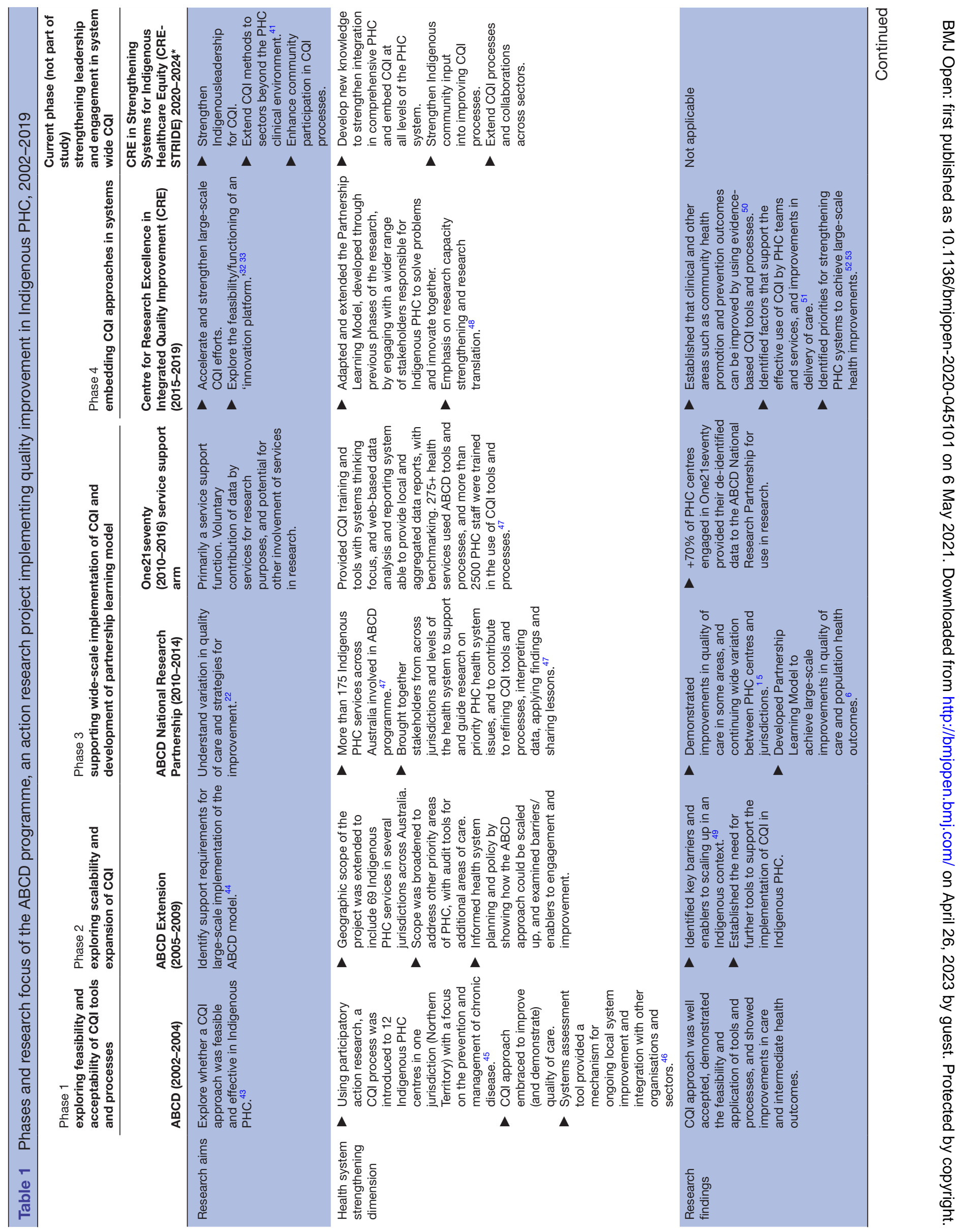




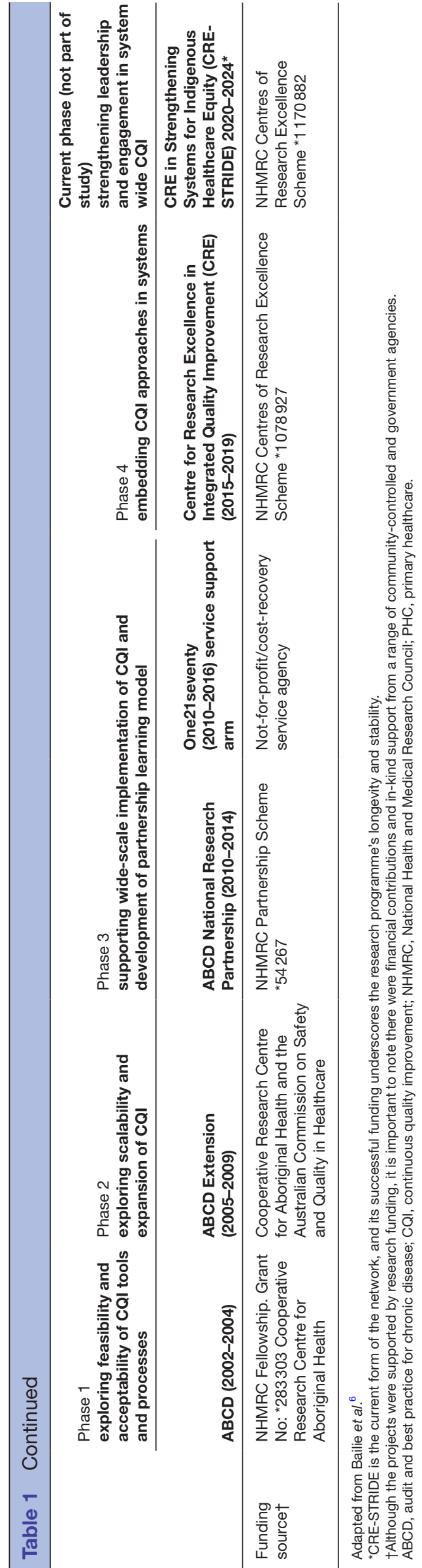

institutes; government departments; health services; affiliates; primary health networks and non-government organisations. Where authors had more than one affiliation listed on the publication, we used the first affiliation provided. Other key points in the categorisation of publications were as follows:

- We used the author's university rather than their specific department and, if named, the research institute rather than the university.

- Where an author's affiliation was nominated as a hospital we used the State Health Department with which these organisations were affiliated.

- 'Affiliates' refers to regional support organisations established to support Indigenous health services, such as Aboriginal Medical Services Alliance Northern Territory.

- 'Health Service' refers to services established primarily to provide PHC to Indigenous people, and includes Aboriginal community-controlled services, government services and private general practice.

- Primary health networks refer to independent regional PHC organisations across Australia that commission rather than provide services, as established by the Australian government in July 2015.

- Non-government organisations refer to not-for-profit organisations that operate independently of government, typically with the purpose of addressing a social or political issue.

\section{Research themes}

Publications were assigned to one of the following three research themes:

1. CQI-related programme activities that address clinical care delivery in the PHC setting: publications that focus on the quality, and variations in delivery, of clinical care, and the application of, or learning from, CQI techniques in relation to a specific aspect of clinical care, for example, child health and chronic illness care.

2. CQI-related programme activities that address social, environmental or behavioural determinants - that is, community health promotion or prevention activities: publications that focus on the application of, or learning from, CQI with a focus on areas such as health promotion, social and environmental conditions, housing, food security and family well-being in general community settings.

3. CQI-related processes and approaches: publications related to CQI programme development (such as study protocols and reviews informing CQI approaches), health systems strengthening, and the development and evaluation of research collaborations and their impact.

In categorising the publications by research themes, abstracts of publications were retrieved and screened by blinded reviewers (JB and RSB). Inconsistencies in reviewer assessments were resolved by consensus.

Role type

We identified all authors who were students or project officers at the time of the publication, and who had authored 
in this capacity. The student category included Public Health Trainees, and Masters, PhD and Medical Honours students. Project officers were identified as those whose primary role supported research, and/or related either to healthcare administration and/or to project work.

\section{Indigenous status}

Coordinating centre records flagged authors who identified as Indigenous.

\section{Gender}

Authors were assigned a male or female category through a number of ways-reviewer knowledge of authors and Google searches.

Where there was uncertainty in allocating the above categories, JB checked with RSB and, when necessary, with the corresponding authors of the manuscripts. Data were entered into an Excel spreadsheet, and then standardised and cleaned by JB and BAP.

\section{Network assembly, visualisation and analysis}

The evolution of the research network was analysed over the four phases displayed in table 1 , with the analysis split into three parts: (1) an analysis of publications by type of organisation represented, research themes, the role of authors, and the Indigenous status of authors; (2) the network analysis of coauthorship between organisations and (3) a core-periphery analysis of organisational position within the network.

Python programming language V.3.7.4 ${ }^{24}$ and the Jupyter Notebook ${ }^{25}$ application accessed through the Anaconda Navigator ${ }^{26}$ interface were used to script all data manipulation and analytical work. Network analyses used the Python package NetworkX, ${ }^{27}$ with visualisations produced with the open-source Gephi program. ${ }^{28}$

We first created a node list containing every organisation and its attributes (unique identifier, organisation name, type and years published), and an edge list representing coauthorship as pairwise combinations of each organisation listed on a publication and its unique attributes.

A single, undirected edge of weight $=1$ was assigned for each organisation pair that shared at least one publication in each phase of the network. For publications that involved only authors from the same organisation, a selfloop edge of weight $=0$ was assigned. No additional weight was given to the number of publications or authors involved or any other attribute. This approach was chosen so that results of the analysis could be directly interpreted in the context of interorganisational collaboration.

Networks were analysed discretely across the four phases. Several network measures (defined in table 2) were used to understand the resulting networks.

Table 2 Theoretical definitions of social network analysis measures, and their meaning in this study

\begin{tabular}{|c|c|}
\hline Measure & Definition, meaning in this study and importance \\
\hline Node & $\begin{array}{l}\text { The basic unit of a network. Nodes represent organisations. The node size is proportional to the no of } \\
\text { publications. }\end{array}$ \\
\hline Density & $\begin{array}{l}\text { The density of a network is the total no of edges divided by the total no of possible edges. It is a widely used } \\
\text { measure that reflects the level of cohesion among network organisations, or the extent to which organisations } \\
\text { collaborated with every other organisation in the network. }\end{array}$ \\
\hline Average degree & $\begin{array}{l}\text { Degree is a count of the no of connections for any given node: the higher the average degree, the more } \\
\text { connected the network. The average no of interorganisational collaborations per organisation. }\end{array}$ \\
\hline $\begin{array}{l}\text { Clustering } \\
\text { coefficient }\end{array}$ & $\begin{array}{l}\text { Clustering is a measure of how many of the nodes connected to a given node are also connected to each } \\
\text { other, which is expressed as a proportion of the total possible connections. The overall clustering coefficient } \\
\text { is the average across the network. Where density tells you how connected the network is, the clustering } \\
\text { coefficient tells you how well connected the various neighbourhoods of the network are. A high clustering } \\
\text { coefficient and low density can be an indication of lots of small groups, loosely connected. }\end{array}$ \\
\hline $\begin{array}{l}\text { Geodesic } \\
\text { distance }\end{array}$ & $\begin{array}{l}\text { The geodesic distance is the shortest path of all possible options between two nodes in the network. The no } \\
\text { of steps it takes to get across a network is a useful measure of how quickly information can be disseminated } \\
\text { to the entire network. }\end{array}$ \\
\hline Diameter & $\begin{array}{l}\text { The diameter of the network is the 'longest short path' between nodes and indicates the maximum no of steps } \\
\text { it would take to get between nodes that are furthest away from each other in the network. The diameter gives } \\
\text { a useful indication of how broad the network is. }\end{array}$ \\
\hline Centralisation & $\begin{array}{l}\text { This reflects how tightly the organisations are connected around the most central point of the network and } \\
\text { how reliant the network may be on a central node. }\end{array}$ \\
\hline $\begin{array}{l}\text { Discrete core- } \\
\text { periphery } \\
\text { model }\end{array}$ & $\begin{array}{l}\text { A network with a core-periphery structure has a 'core' of nodes densely connected to each other and to } \\
\text { others, and 'periphery' nodes in the less-connected 'periphery' that are connected only to core nodes. }\end{array}$ \\
\hline
\end{tabular}


The analysis of network position at the organisational level uses discrete core-periphery analysis ${ }^{29}$ to identify organisations that are well connected to each other (the core) as distinct from those less well connected (the periphery). To detect the core-periphery, we used the Borgatti and Everett ${ }^{29}$ algorithm and the non-parametric statistical test devised by Kojaku and Masuda. ${ }^{30}$

\section{Patient and public involvement}

No patients or members of the public were involved in the design, analysis or reporting of this study.

\section{RESULTS}

We identified 128 publications written by 308 authors, with a median of six authors per publication $(\mathrm{IQR}=4-9.25)$, representing 79 different organisations (table 3). Most authors (182 or $59.5 \%$ ) contributed just one publication, while $18(5.9 \%)$ contributed 10 or more. The chief investigator (RSB) of the original ABCD programme coauthored 97 of the 128 publications (online supplemental file 1).

\section{Linking people from a variety of organisations}

As shown in table 3, there was an increase in the number and type of different organisations in the network, with considerable growth from phase 3 (24 organisations) to phase 4 (72 organisations). Of note, the number of universities and research institutes increased from 15 in phase 3 to 45 in phase 4, while Health Services rose from 2 to 11 and international organisations increased to 8 . This growth in different organisations participating in the research network over time was a result of existing organisations continuing to publish together (yellow nodes), and new organisations coauthoring (blue nodes) (figure 1). A few organisations ceased publishing as part of the network (red nodes), shown as 'isolates'.

\section{Relationships of organisations and structural characteristics}

The structural characteristics of the networks are based on the indicators shown in table 3. Our analysis of the network data shows a decrease in the network density. In phase 2 and 3, the research network was relatively well connected with $\sim 46 \%$ of all possible relationships in the network actualised. However, in phase 4 , with $\sim 11 \%$ of all possible links existing between organisations, there was less connectivity between organisations. The decrease in network density was linked to an increase in the number of organisations publishing together in phase 4 , as noted above (table 3), and an increase in the scope of CQI publications. However, the average clustering coefficient remained high across all phases (1, 0.80, 0.86 and 0.81 , respectively), indicating a strong tendency for multiple organisations to be collaborating on individual publications. Part of this high effect is a natural consequence of authors publishing together-it introduces triangles of collaborating authors, thereby increasing the clustering coefficient.
From table 3, we note that the average number of organisations collaborating directly on publications (average node degree) steadily increased from 2 in phase 1 , to $5,10.9$ and then 8.1 in subsequent phases. This is a sign that organisations collaborated more widely over time, with a small decrease in phase 4 . On average, publications involved 3.4 organisations, with 3.5 publications per organisation. This indicates a maturation of organisational relationships, typically creating more than one publication from each collaboration. Furthermore, network diameter was at-most 3 (phase 4) and geodesic distance was at-most 2.1 (phase 4). This indicates a close-knit cohesive network in which organisations were connected by no more than two other organisations, resulting in the network being unlikely to fragment and able to disseminate information quickly.

The degree-centralisation from phase 2 was 0.65 followed by 0.57 and 0.55 in the subsequent phases. Conversely, the core-periphery analysis produced strong results in each phase (see table 3 ). These analyses indicate that in all four phases the network was not connected via a single dominant central organisation but rather by a core-periphery structure that points to a more collaborative network. Intersectoral collaboration (research, government and/or health services) were represented in the core for phases 2 and 3 (green nodes in figure 2). In phase 4 , the organisations comprising the core were all universities or research institutes, indicating that government departments and health services were more likely to publish with them than with each other.

\section{Equity in authorship}

Female first authors increased over time, growing from none in phase 1 to $84 \%(\mathrm{n}=76)$ in phase 4 (table 3$)$, with about $28 \%$ of the publications having a female senior or last author in all phases after the first. Although the number of publications led by Indigenous authors remained low, over time there was an increasing number and percentage with at least one Indigenous author. The greatest expansion was observed from phase 3 to phase 4 when the number of publications with at least one Indigenous author increased from 13 to 56 (table 3).

\section{Providing opportunities for capacity strengthening}

Over time there was also an increase in absolute number (but a decline in percentage) of publications with at least one student or project officer author, from 2 in phase 1 to 52 in phase 4 (table 3). Phase 4 also saw an increase in student or project officer as lead author, with the largest growth in phase $4(28 \%, \mathrm{n}=25)$ representing a twofold increase from phase $3(14 \%, \mathrm{n}=3)$.

\section{Expansion of research themes}

As the network evolved there was a notable growth in publications related to CQI and clinical care, an increase in publications related to social, environmental and behavioural determinants of health, and on the development of processes and approaches for CQI (table 3). The 
Table 3 Coauthorship characteristics, by phases and total 2002-2019

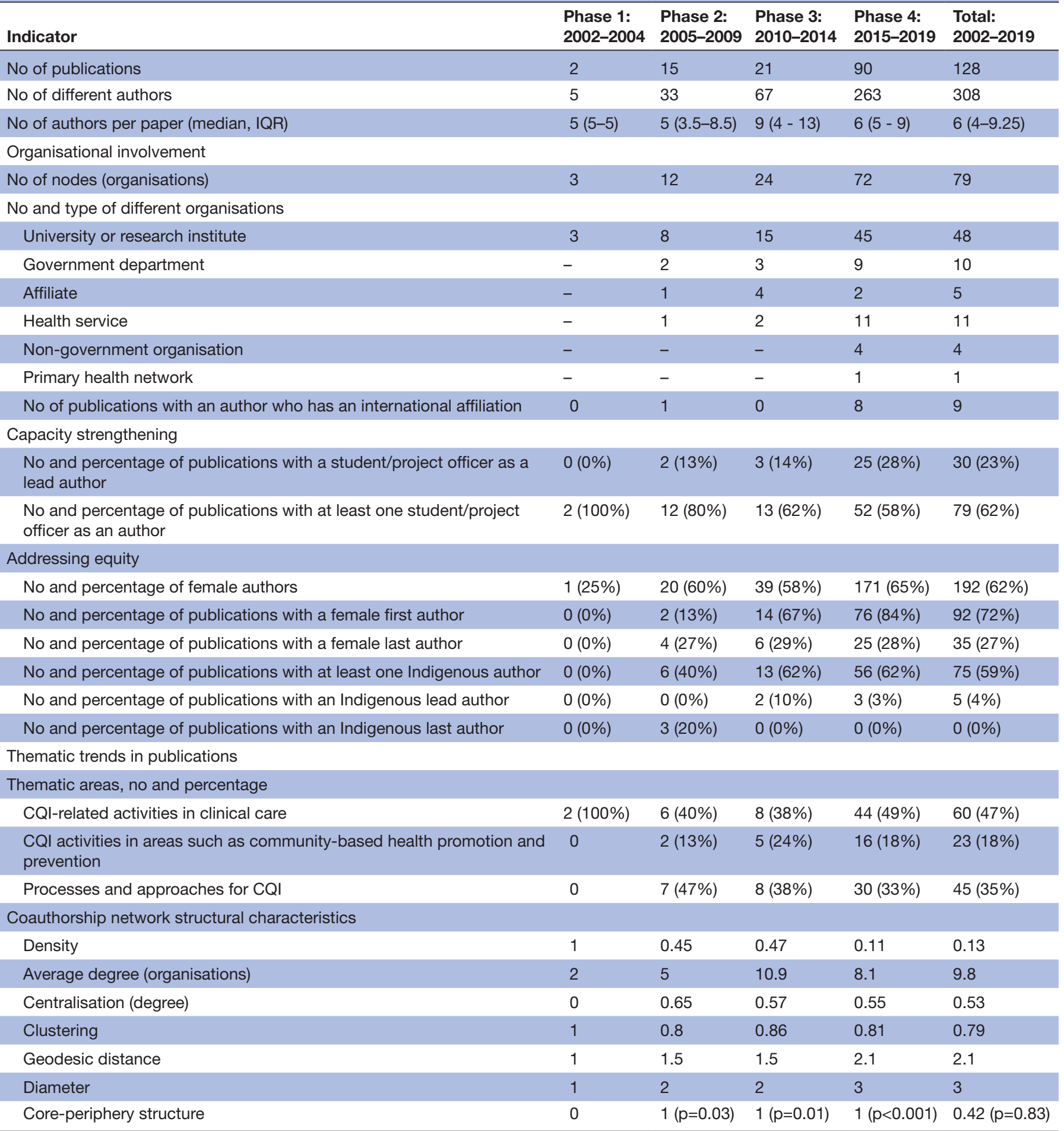

CQI, continuous quality improvement.

growth in research themes in phase 4 was consistent with the increase observed in the number of publications and organisations involved in this phase, and the emergence of new core organisations. Online supplemental file 2 contains a listing of all publications and their assigned category of research themes.

\section{DISCUSSION}

This study examined the growth of and changes in an Australian quality improvement research network over an 18-year period by assessing coauthorship of publications using network analysis. Key findings include an expansion in the number of publications; a greater number and diversity of organisations coauthoring; improvements in capacity strengthening measures reflected in increased 
Phase 12002-2004

REs

RES
Phase 2 2005-2009

(RES

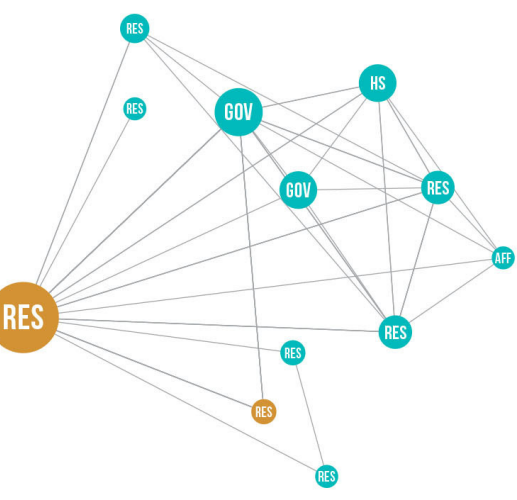

Figure 1 Evolution of the quality improvement research network, 2002-2019.

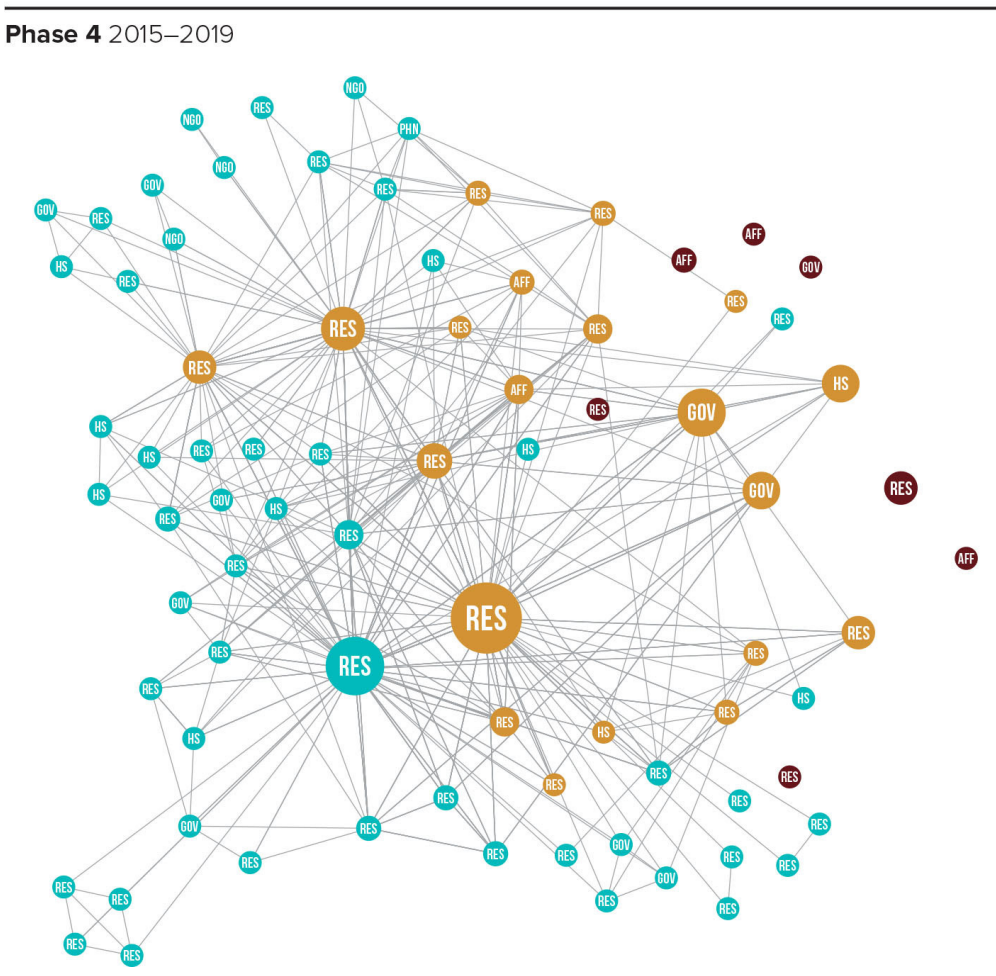

(1) PHI Primary Health Network

BES

New to network

Left network

Existing or former member

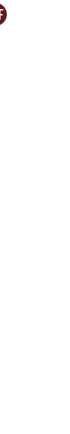

Phase 3 2010-2014

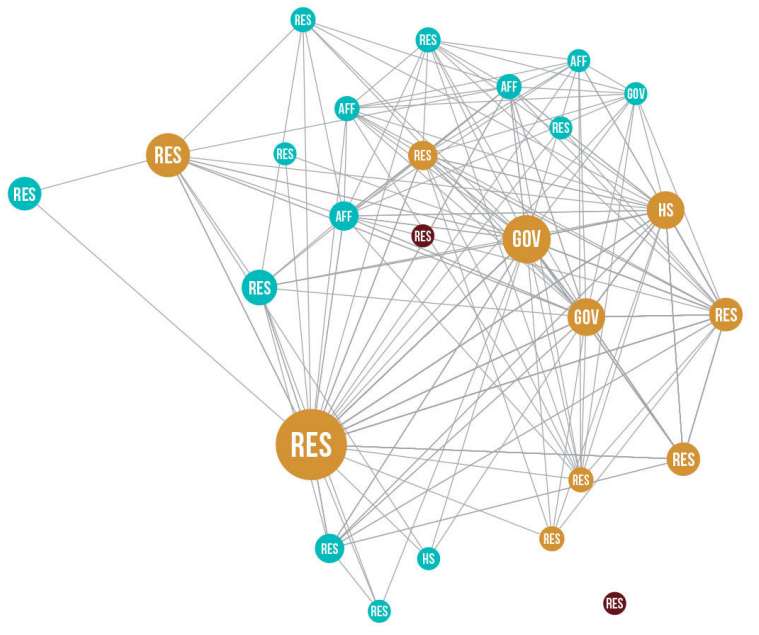

RES University or Research Institute

HS Health Service

GOV Government Department

AFF Affiliate

(160) Non-Government Organisation 
Phase 1 2002-2004

RES

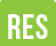

Phase 2 2005-2009

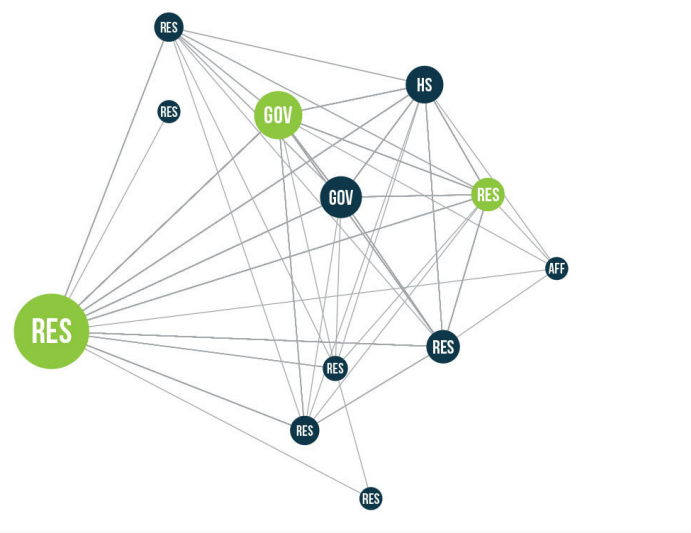

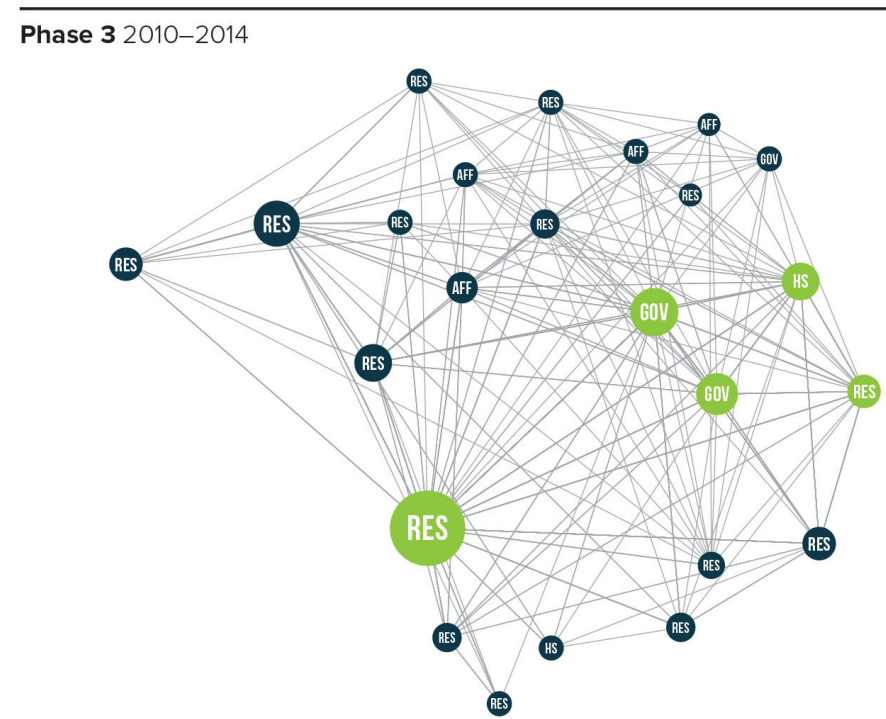

RES University or Research Institute

HS Health Service

GOV Government Department

AFF Affiliate

NGO Non-Government Organisation

PHI Primary Health Network

Core organisations

Periphery organisations

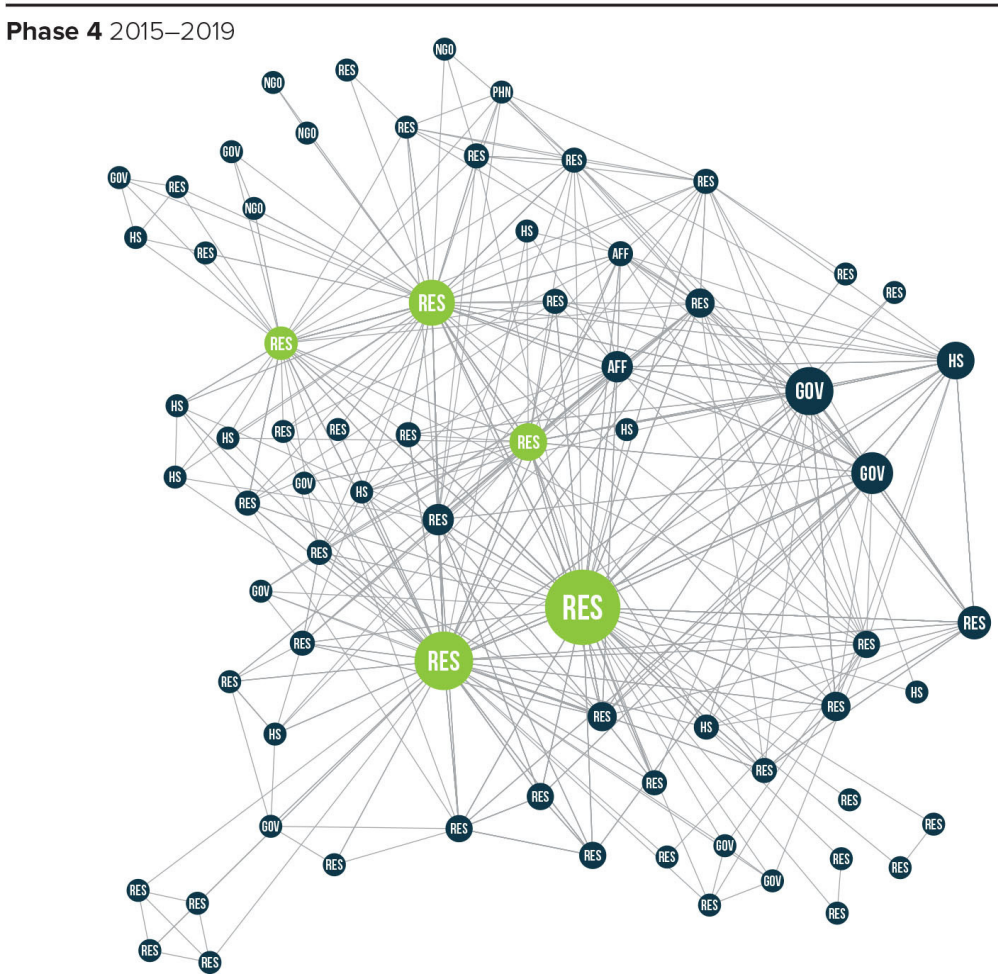

Figure 2 Core periphery analysis by phases, 2002-2019. 
student and project officer authorship and first author position; and a broadening or scaling-out ${ }^{31}$ of quality improvement work to other thematic areas. There is evidence, too, that the research network linked people from a variety of organisations, including universities or research institutes, PHC services and government departments, who might otherwise have never worked together. This expansion potentially extended both the impact of the network and of the organisations involved.

The characteristics of the network showed a strong collaborative structure and a maturation of organisational relationships, with more than one publication typically developed by each collaborating organisation. Network analyses indicated a core-periphery structure of organisations connected to each other in each phase, rather than a network structured around a single central organisation. As there was the same chief investigator throughout the study period, this finding of a coreperiphery structure indicates the network expanded to have other core organisations over time, and was not just centred on the chief investigators organisation. In phases 2 and 3, the relationships between research institutions and government departments were well represented in the network core. The network's founding partners maintained a consistent presence as members of the core, indicating that it remained dependent on these partners for collaboration. However, new core organisations emerged when key authors changed institutions, reflecting that individuals stimulated the expansion of core members. For example, a result of key individuals moving institutions and growing the publishing base was a phase 4 core comprised solely of universities and research institutes, whilehealth service and government organisations were part of the core in the earlier phases. This change occurred despite a large increase in the number and type of organisations involved in the network in phase 4 .

Network growth was greatest in phase 4, when funding was received from the Australian government's National Health and Medical Research Council (NHMRC) to establish a CRE and the network's structure and function $^{12}$ evolved to that of an 'innovation platform. ${ }^{32}$ Used as a vehicle to stimulate and support multistakeholder collaboration and learning, "innovation platforms' provide a space of interaction to facilitate the development and emergence of innovations when there are complex, system-wide issues requiring coordinated action and collective problem solving. Most extensively applied in international agricultural development, and to a limited extent in health, innovation platforms differ from other networks by the incorporation of a wider network of stakeholders at multiple levels of the system and in different roles; the concept of 'sector boundary spanning' that brings in stakeholders from other sectors to assist in developing healthcare solutions; and application of continuous reflection, learning and adaptation as central design elements. ${ }^{32} 33$

These findings support previous literature that researchers tend to collaborate with like-minded others, but that this tendency toward homophily can be disrupted by implementing policies that encourage interdisciplinary collaboration and purposeful research translation-such as was done with the innovation platform. ${ }^{14}$ Although the purposeful adjustment to an 'innovation platform' was associated with an expansion of activity among the network and new thematic scope in publications, this acceleration could also reflect other inter-related factors, such as longer-term relationships, and an increase in funding.

Furthermore, the earlier phases were focused on supporting PHC services to implement and embed quality improvement techniques through participatory action research. Access to the CQI dataset formed the basis of research collaborations between those services and university and research institutes to undertake data analyses that resulted in publications up to 2019. Though there were 175 PHC services providing data to the research collaboration, only 11 health services coauthored publications. While not necessarily coauthors, health services made important contributions to implementing research, collecting data and importantly-to interpretation and analysis of findings.

Our findings build on a prior social network analysis of partners in the research network which was undertaken as part of an interim evaluation in phase 3 of the research network. Cunningham $e t a l^{34}$ found an increase in network density (43\%-59\%) from 2013 to 2014, indicating an increase over time in connectivity and communication between partner organisations. A major element in achieving the goals of that phase of research was the network's focus on developing a shared database of deidentified CQI data from Indigenous PHC centres. ${ }^{34}$ The importance to the research network of collecting and sharing data is supported by the experiences of other research collaborations. ${ }^{35}$ Furthermore, the high level of trust identified across the network is indicative of a properly functioning collaboration. ${ }^{37}$ The growth in phase 4 leveraged the high level of trust already established. The decreasing degree of centralisation scores are consistent with findings reported by Cunningham $e t a l^{34}$ and reflect the shift towards more organisations taking a greater role in publishing. Increasing the number of diverse collaborations and creating a more decentralised network has been shown to improve productivity and increase the potential for high-impact science. ${ }^{38}$

Equity and capacity strengthening are promoted as core elements of research networks. ${ }^{12} 39$ The research network, particularly when operating as an innovation platform, made some progress in addressing concerns about the imbalances between Indigenous and non-indigenous authors when writing about Indigenous issues. However, despite an increased number of publications with Indigenous authors, especially in phase 4 , there remains a paucity of Indigenous first or senior/last authors. Further work is needed to redress the inequities these imbalances represent, a concern echoed in global health literature. ${ }^{40}$ The latest iteration of the research network was recently 
launched with funding for a new CRE in Strengthening Systems for Indigenous Health Care Equity (2020-2024 (NHMRC Grant Id \#1170882). This Centre marks the beginning of a new Indigenous leadership structure for the research network with more than half of the research investigators, including the chief investigator, identifying as Indigenous. It also aims to extend and further support the use of CQI methods in sectors with responsibility for addressing social and cultural determinants of health and to enhance community participation in CQI processes. ${ }^{41}$

\section{Strengths and limitations of the study}

A study strength was the long time frame of 18 years of publications. Although coauthorship is only one indicator of collaboration, there are several advantages to relying on it as a proxy for assessing the level of research collaboration, including its verifiability, stability over time, availability of data in the public domain and ease of measurement. ${ }^{11}$

As the aim of the study was to assess growth and change in the research collaboration over time, we applied an unweighted method to the network analysis. This approach was chosen for a number of reasons. First, the interpretability would be compromised by weighting edges, in the context of the questions we wished to answer. We moved all of the information that would have otherwise been embedded into a weight to separate descriptive analyses available in table 3 . Second, given the temporal nature of collaborations we did not wish to make erroneous assumptions that quantity of publications is a substitute for quality. For example, it is difficult to compare a collaboration that generates only one high impact publication to a collaboration that may produce a larger number of lower impact publications. Weighting by publication numbers could therefore introduce a bias that may lead to erroneous interpretation of the findings.

Limitations of this study include: (1) many collaborative efforts are not reflected in coauthorship metrics. We are undertaking other studies to address this as part of the overall evaluation of the CRE-IQI. Other measures of collaborative ties include having coinvestigators on submitted or funded grants, on conference presentations and as authors of grey literature, all of which may be useful to broaden the definition of collaboration in our innovation platform. However, we assumed that, in most cases, coauthorship indicates an active cooperation between partners beyond the simple exchange of material or information. (2) This analysis does not capture the collaborations that continue to occur through coauthorship or other means that are not necessarily related to the research network. For example, a collaboration formed by coauthoring on a CRE-IQI manuscript might lead to collaboration on other projects and research not reflected in this analysis. (3) Because there is a substantial lead time for an academic publication, a writing collaboration that might have commenced in an earlier phase of work may not have been published until a later phase. Thus, publication in one phase can arise from substantial work in a previous phase. (4) Although multiple authorship affiliations are increasingly recognised as facilitating knowledge exchange and becoming more widespread, ${ }^{42}$ our analysis does not include the multiple affiliations of many of the authors and so may under-report the level of collaboration. Similarly, only representing the university affiliation, and not the actual department in which an author works, obscures collaboration between departments in the same university. (5) Three of the 11 authors on this manuscript (RSB, JB and VM) had published more than 20 manuscripts included in this analysis, and RSB was the chief investigator on the research network during this period. Given this, and to mitigate against bias, BAP who has not published as part of this network undertook the network analysis and there was a blind review process for categorising the manuscripts, with discrepancies discussed.

To the best of our knowledge, this study is the first to describe a CQI research network using coauthorship network analysis. While the generalisability of the findings may be limited to similar networks, the methodological approach could readily be transferred. In this study we did not set out to demonstrate a link between an expansion of the collaboration and engagement with impact or improvement in the quality of care. However, it is widely recognised in the literature, that increasing collaboration and engagement across health services, researchers and policy-makers is a critically important element along the causal change pathway to improving the quality of care and achieving impact. Methods such as coauthorship analysis are useful for demonstrating a pathway to research impact related to engagement, which traditionally tends to rely on the quantity of outputs rather than on the strengthening of networks and the scope of work undertaken.

\section{CONCLUSION}

Over the 18-year time frame, collaboration in publications increased with network consolidation and expansion. Publication outputs accelerated in the final phase, coinciding with a broader thematic focus and an increase in the number and diversity of participating organisations. This expansion occurred largely due to the cumulative effect of building trust and relationships over time, including the development of a comprehensive dataset for use by all stakeholders. The findings highlight the benefits of long-term relationship building among diverse partners to support participatory research in quality improvement. Increased productivity was associated with increased authorship diversity and a decentralised network, suggesting these may be important factors in enhancing research impact and advancing the knowledge and practice of CQI in PHC. Despite improvements, further work is needed to address inequities in female authorship and Indigenous authorship. The coauthorship analysis has been useful for demonstrating research impacts related 
to collaboration, which are not well captured by metrics such as quantity of outputs.

\section{Author affiliations}

${ }^{1}$ University Centre for Rural Health, The University of Sydney, Lismore, New South Wales, Australia

${ }^{2}$ School of Public Health, The University of Sydney, Sydney, New South Wales, Australia

${ }^{3}$ The George Institute for Global Health, University of New South Wales, Sydney, New South Wales, Australia

${ }^{4}$ Menzies School of Health Research, Charles Darwin University, Brisbane,

Queensland, Australia

${ }^{5}$ School of Health, Medical and Applied Sciences, Central Queensland University,

Cairns, Queensland, Australia

${ }^{6}$ School of Public Health, DePaul University, Chicago, Illinois, USA

Twitter Jodie Bailie @JodieBailie1, Alison Frances Laycock @AlisonLaycock2, Seye Abimbola @seyeabimbola, Ross Stewart Bailie @RossBailie, Frances Clare Cunningham @CunninghamF_C, Veronica Matthews @DrVMatthews, Roxanne Gwendalyn Bainbridge @DrRoxBainbridge, Kathleen Parker Conte @kpconte and David Peiris@davidpeiris

Acknowledgements The development of this manuscript would not have been possible without the active support, enthusiasm and commitment of staff in participating primary health are services, and members of the research collaboration various phases of the research collaboration. We would like to acknowledge the Centre for Research Excellence in Integrated Quality Improvement (CRE-IQI) evaluation working group for its role in guiding the implementation of the multi-pronged evaluation of the CRE-IQI: Ms Jodie Bailie, Professor Roxanne Bainbridge, Professor Ross Bailie, Dr Alison Laycock, Mr Boyd Potts, Dr Shanthi Ramanathan, Professor Andrew Searles, Dr Frances Cunningham and Professor Chris Doran. We would like to thank Ms Kerryn Harkin for compiling and maintaining project records, and for organising workshops and meetings, Dr Frances Cunningham for her contributions to the application of the network methodology, Dr Dan Chamberlain for his expert review of the methodology, Ms Svetlana Andrienko for the reproduction of images and Ms Jane Yule for her editing and proofreading support.

Contributors Study conceptualisation: JB, BAP, RSB, DP Data curation: JB, BAP, RSB Formal analysis: BAP, JB Data interpretation: JB, BAP, AFL, SA, RSB, FCC, VM, RGB, KPC, MEP, DP Funding acquistion for study: RSB, JB Methodology: JB, BAP, FCC, RSB, DP Project administration: JB Supervision: DP, FCC Data visualisation: JB, BAP Writing - original draft: JB, BAPWriting, criticial intellectual input \& review: JB, BAP, AFL, SA, RSB, VM, RGB, KPC, MEP, DP

Funding The National Health and Medical Research Council (www.nhmrc.gov. au) funded the Centre for Research Excellence in Integrated Quality Improvement (\#1078927). In-kind support has been provided by a range of community-controlled and government agencies.

Competing interests The authors declare that this research was conducted in the absence of any commercial or financial relationships that could be construed as a potential conflict of interest.

Patient consent for publication Not required.

Ethics approval University of Sydney Human Research Ethics Committee (Project 2018/206) and the Human Research Ethics Committee of the Northern Territory Department of Health and Menzies School of Health Research (Project 2018-3105).

Provenance and peer review Not commissioned; externally peer reviewed.

Data availability statement Data are available on reasonable request. The data set is available from the corresponding author on reasonable request and if consistent with the projects's ethics approvals.

Supplemental material This content has been supplied by the author(s). It has not been vetted by BMJ Publishing Group Limited (BMJ) and may not have been peer-reviewed. Any opinions or recommendations discussed are solely those of the author(s) and are not endorsed by BMJ. BMJ disclaims all liability and responsibility arising from any reliance placed on the content. Where the content includes any translated material, BMJ does not warrant the accuracy and reliability of the translations (including but not limited to local regulations, clinical guidelines, terminology, drug names and drug dosages), and is not responsible for any error and/or omissions arising from translation and adaptation or otherwise.
Open access This is an open access article distributed in accordance with the Creative Commons Attribution Non Commercial (CC BY-NC 4.0) license, which permits others to distribute, remix, adapt, build upon this work non-commercially, and license their derivative works on different terms, provided the original work is properly cited, appropriate credit is given, any changes made indicated, and the use is non-commercial. See: http://creativecommons.org/licenses/by-nc/4.0/.

Author note RSB was the chief investigator of the research network from 2002 to 2019. RSB, JB, VM, AFL, FCC, RB and AFL had published five or more publications as part of this research network. RGB and VM are both Indigenous researchers: RB is from the Gungarri/Kunja nations in South-Western Queensland and VM from the Quandamooka community on North Stradbroke Island, Queensland. JB, BAP, RSB, DP, AFL, SA, KPC, MEP and FCC are non-Indigenous researchers. All authors have a long-standing commitment to improving health outcomes for Aboriginal and Torres Strait Islander people.

\section{ORCID iDs}

Jodie Bailie http://orcid.org/0000-0003-4393-5773

Alison Frances Laycock http://orcid.org/0000-0001-7756-4398

Seye Abimbola http://orcid.org/0000-0003-1294-3850

Ross Stewart Bailie http://orcid.org/0000-0001-5966-3368

Frances Clare Cunningham http://orcid.org/0000-0002-9783-9165

Veronica Matthews http://orcid.org/0000-0002-1319-257X

Roxanne Gwendalyn Bainbridge http://orcid.org/0000-0003-1206-8072

Kathleen Parker Conte http://orcid.org/0000-0002-5429-429X

Megan Elizabeth Passey http://orcid.org/0000-0001-5766-0235

David Peiris http://orcid.org/0000-0002-6898-3870

\section{REFERENCES}

1 Bailie R, Matthews V, Larkins S, et al. Impact of policy support on uptake of evidence-based continuous quality improvement activities and the quality of care for Indigenous Australians: a comparative case study. BMJ Open 2017;7:e016626.

2 Sibthorpe B, Gardner K, Chan M, et al. Impacts of continuous quality improvement in Aboriginal and Torres Strait Islander primary health care in Australia. J Health Organ Manag 2018;32:545-71.

3 Taylor MJ, McNicholas C, Nicolay C, et al. Systematic review of the application of the plan-do-study-act method to improve quality in healthcare. BMJ Qual Saf 2014;23:290-8.

4 O'Neill SM, Hempel S, Lim Y-W, et al. Identifying continuous quality improvement publications: what makes an improvement intervention 'CQI'? BMJ Qual Saf 2011;20:1011-9.

5 Matthews V, Schierhout G, McBroom J, et al. Duration of participation in continuous quality improvement: a key factor explaining improved delivery of type 2 diabetes services. BMC Health Serv Res 2014;14:578.

6 Bailie R, Matthews V, Brands J, et al. A systems-based partnership learning model for strengthening primary healthcare. Implement Sci 2013;8:143.

7 Dixon-Woods M. How to improve healthcare improvement-an essay by Mary Dixon-Woods. BMJ 2019;367:I5514.

8 Oliver K, Kothari A, Mays N. The dark side of coproduction: do the costs outweigh the benefits for health research? Health Res Policy Syst 2019;17:33.

9 Holbrook JA, Wixted B, Lewis BS. The structure and construction of formal research networks: a policy oriented understanding of stakeholder engagement. Simon Fraser University,Vancouver, BC, 2011. Available: http://summit.sfu.ca/item/13636

10 Varda DM, Retrum JH. An exploratory analysis of network characteristics and quality of interactions among public health Collaboratives. J Public Health Res 2012;1:27-176.

11 Katz JS, Martin BR. What is research collaboration? Res Policy 1997;26:1-18.

12 VanderZanden A, Langlois EV, Ghaffar A, et al. It takes a community: a landscape analysis of global health research consortia. BMJ Glob Health 2019:4:e001450.

13 Fonseca BdePFE, Sampaio RB, Fonseca MVdeA, et al. Coauthorship network analysis in health research: method and potentia use. Health Res Policy Syst 2016;14:34.

14 Fagan J, Eddens KS, Dolly J, et al. Assessing research collaboration through co-authorship network analysis. J Res Adm 2018;49:76-99.

15 Newman MEJ. Coauthorship networks and patterns of scientific collaboration. Proc Natl Acad Sci U S A 2004;101:5200-5.

16 Schneider EC, Sarnak DO, Squires D. Mirror mirror 2017: international comparison reflects flaws and opportunities for better 
U.S. health care. New York, NY: Commonwealth Fund, 2017. https:// interactives.commonwealthfund.org/2017/july/mirror-mirror/

17 Australian Health Ministers' Advisory Council. Aboriginal and Torres Strait Islander health performance framework. Canberra: Department of the Prime Minister and Cabinet, 2017. https://www.niaa.gov.au/ resource-centre/indigenous-affairs/health-performance-framework2017-report

18 Bailie J, Schierhout G, Laycock A, et al. Determinants of access to chronic illness care: a mixed-methods evaluation of a national multifaceted chronic disease package for Indigenous Australians. BMJ Open 2015;5:e008103.

19 Australian Indigenous HealthInfoNet. Overview of aboriginal and torres strait islander health status 2019. Perth: Australian Indigenous HealthlnfoNet, 2020. https://healthinfonet.ecu.edu.au/learn/healthfacts/overview-aboriginal-torres-strait-islander-health-status/

20 Durey A, Thompson SC. Reducing the health disparities of Indigenous Australians: time to change focus. BMC Health Serv Res 2012;12:151.

21 Shortell SM, Bennett CL, Byck GR. Assessing the impact of continuous quality improvement on clinical practice: what it will take to accelerate progress. Milbank Q 1998;76:593-624.

22 Bailie R, Si D, Shannon C, et al. Study protocol: national research partnership to improve primary health care performance and outcomes for Indigenous peoples. BMC Health Serv Res 2010;10:129.

23 Hayward MN, Mequanint S, Paquette-Warren J, et al. The FORGE AHEAD clinical readiness consultation tool: a validated tool to assess clinical readiness for chronic disease care mobilization in Canada's first nations. BMC Health Serv Res 2017;17:233.

24 Python Software Foundation. Python language reference. Available: hhttp://www.python.org [Accessed 25 May 2020].

25 Kluyver T, Ragan-Kelley B, Pérez F. Jupyter Notebooks-a publishing format for reproducible computational workflows. ELPUB 2016:87-90.

26 Anaconda Software Distribution. Anaconda, 2016. Available: https:// anaconda.com

27 Hagberg A, Swart P, Chult D S. Exploring network structure, dynamics, and function using NetworkX. Los Alamos, NM: Los Alamos National Lab.(LANL), 2008.

28 Bastian M, Heymann S, Jacomy M, eds. Gephi: an open source software for exploring and manipulating networks. Third International AAAl Conference on Weblogs and Social Media, 2009.

29 Borgatti SP, Everett MG. Models of core/periphery structures. Soc Networks 2000;21:375-95.

30 Kojaku S, Masuda N. A generalised significance test for individual communities in networks. Sci Rep 2018;8:7351.

31 Aarons GA, Sklar M, Mustanski B, et al. "Scaling-out" evidencebased interventions to new populations or new health care delivery systems. Implement Sci 2017;12:111.

32 Bailie J, Cunningham FC, Bainbridge RG, et al. Comparing and contrasting 'innovation platforms' with other forms of professional networks for strengthening primary healthcare systems for Indigenous Australians. BMJ Glob Health 2018;3:e000683.

33 Bailie J, Laycock AF, Peiris D, et al. Using developmental evaluation to enhance continuous reflection, learning and adaptation of an innovation platform in Australian Indigenous primary healthcare. Health Res Policy Syst 2020;18:45.

34 Cunningham FC, Matthews V, Sheahan A, et al. Assessing collaboration in a national research partnership in quality improvement in Indigenous primary health care: a network approach. Front Public Health 2018;6:182.

35 Aveling EL, Martin G, Armstrong N. Quality improvement through clinical communities: eight lessons for practice. Journal of health organization and management. 2012. J Health Organ Manag 2012;26:158-74.

36 NIMH Collaborative Data Synthesis for Adolescent Depression Trials Study Team, Perrino T, Howe G, et al. Advancing science through collaborative data sharing and synthesis. Perspect Psychol Sci 2013;8:433-44.

37 Mattessich P, Johnson K. Collaboration: what makes it work. In: A review of research literature on factors influencing successful collaborations. 3rd edn. New York: Fieldstone Alliance, 2018.

38 Yousefi-Nooraie R, Akbari-Kamrani M, Hanneman RA, et al. Association between co-authorship network and scientific productivity and impact indicators in academic medical research centers: a case study in Iran. Health Res Policy Syst 2008;6:9.

39 Parker M, Kingori P. Good and bad research collaborations: researchers' views on science and ethics in global health research. PLoS One 2016;11:e0163579.

40 Abimbola S. The foreign gaze: authorship in academic global health. BMJ Glob Health 2019;4:e002068.

41 Laycock A, Conte $\mathrm{K}$, Harkin $\mathrm{K}$, et al. Improving the quality of primary health care for Aboriginal and Torres Strait Islander Australians. centre for research excellence in integrated quality improvement 2015-2019: messages for action, impact and research. Lismore NSW: University Centre for Rural Health, The University of Sydney, 2019. https://ucrh.edu.au/cre-iqi-resources/

42 Hottenrott $\mathrm{H}$, Lawson $\mathrm{C}$. A first look at multiple institutional affiliations: a study of authors in Germany, Japan and the UK. Scientometrics 2017:111:285-95.

43 Bailie RS, Si D, Robinson GW, et al. A multifaceted health-service intervention in remote Aboriginal communities: 3-year follow-up of the impact on diabetes care. Med J Aust 2004:181:195-200.

44 Bailie R, Si D, Connors C, et al. Study protocol: audit and best practice for chronic disease extension (ABCDE) project. BMC Health Serv Res 2008;8:184.

45 Bailie RS, Togni SJ, Si D, et al. Preventive medical care in remote Aboriginal communities in the Northern Territory: a follow-up study of the impact of clinical guidelines, computerised recall and reminder systems, and audit and feedback. BMC Health Serv Res 2003;3:15.

46 Cunningham FC, Ferguson-Hill S, Matthews V, et al. Leveraging quality improvement through use of the systems assessment tool in Indigenous primary health care services: a mixed methods study. BMC Health Serv Res 2016;16:583.

47 Bailie J, Schierhout G, Cunningham F, et al. Quality of primary health care for Aboriginal and Torres Strait Islander people in Australia: key research findings and messages for action from the $A B C D$ national research partnership. Menzies School of Health Research, 2015. https://apo.org.au/node/55532

48 McPhail-Bell K, Matthews V, Bainbridge R, et al. An "all teach, all learn" approach to research capacity strengthening in Indigenous primary health care continuous quality improvement. Front Public Health 2018;6:107.

49 Schierhout G, Brands J, Bailie R. Audit and best practice for chronic disease extension project, 2005-2009: final report. The Lowitja Institute, Melbourne, 2010. https://www.lowitja.org.au/content/ Document/ABCDE Report2011.pdf

50 McCalman J, Bailie R, Bainbridge R, et al. Continuous quality improvement and comprehensive primary health care: a systems framework to improve service quality and health outcomes. Front Public Health 2018;6:76.

51 Bailie J, Laycock A, Matthews V, et al. System-level action required for wide-scale improvement in quality of primary health care: synthesis of feedback from an interactive process to promote dissemination and use of aggregated quality of care data. Front Public Health 2016;4:86.

52 Bailie J, Matthews V, Laycock A, et al. Rigorous follow-up systems for abnormal results are essential to improve health outcomes for Aboriginal and Torres Strait Islander people. Aust J Prim Health 2018:24:1-3

53 Laycock A, Bailie J, Matthews V, et al. Interactive dissemination: engaging stakeholders in the use of aggregated quality improvement data for system-wide change in Australian Indigenous primary health care. Front Public Health 2016:4:84. 